\title{
Cross-country Comparison of Grain Processing Manufacturing Export Technical Complexity and Its Influencing Factors
}

\author{
Zhenjun Cai \\ School of Business, Hunan International Economics University, Changsha, Hunan, China
}

\begin{abstract}
The result of measuring the technical complexity of China's and OECD countries' grain export based on houseman's export technical complexity model shows that there are 10 countries with high technical complexity of grain export, with the United States, Canada and Australia in the top three, 9 countries with medium and 16 countries with low export technical complexity. In 2019, the technical complexity of China's grain exports was US\$ 890, ranking 34th among the sample countries, with an average increase of $28 \%$ during the sample period. Upgrading the level of agricultural modernization, expanding the scale of grain production, and Manufacturing technology spillover are conducive to increasing the technical complexity of export.
\end{abstract}

Keywords: International trade, export technology complexity, grain processing industry

\section{Introduction}

Cereal products are an important component of agricultural products. Improving the technical complexity of their export is an important measure to cope with the foreign trade impact that may occur under the COVID-19 outbreak and to create a sustainable export competitive advantage. According to the UN merchandise trade statistics, in 2019, China's agricultural exports climbed from the eighth place in the world when it joined the WTO to the top four, accounting for $5.41 \%$ of the world's total, up from $3.82 \%$. The trade deficit amounted to US\$ 71.28 billion, representing a year-on-year increase of $24.2 \%$, with the deficit in cereal products accounting for a particularly large proportion. In recent years, the research on whether China's agricultural export is "large but not strong" shows that although China's agricultural export is among the top few, it has a low level of overall export technical complexity and even a declining export competitive advantage.

Technical complexity is closely related to the income level of an economy. In practical research, many scholars use GDP per capita (index) as an alternative indicator of income. Hausmann et al. constructed a measurement model of export technology complexity based on this theoretical hypothesis, and concluded that the higher the export technology complexity of a country, the higher the productivity of its products [1]. Du et al. took the market share as the weight, and found that its measurement results were easily affected by the "large country effect" of trade [2]. Fan et al. expressed the labor productivity by the logarithmic per capita GDP, and further excluded the "large country effect" of trade by revealed comparative advantage index weighting of each product in each country [3]. The research on export technology complexity has reached a broad consensus that the complexity of export technology is an important manifestation of the country's export competitive advantage. Some scholars have introduced the complexity of export technology into the research on the competitive advantage of agricultural products export technology, and have drawn the general conclusion that China's overall export of agricultural products has a low level of technological complexity and a low level of technological structure, and a few studies have even drawn the conclusion that the technological complexity of China's agricultural products export has regressed. He et al. thought that the technical structure of China's agricultural exports was still low compared with Japan and South Korea [4]. Yin et al. pointed out that although the export scale of China's agricultural products has gradually expanded and the export structure has been gradually optimized and upgraded, the international competitiveness and international status have not yet improved, and the export technology complexity index is at a low level [5-7]. Sun et al. believed that China's agricultural product export technology structure as a whole has achieved a significant upgrade, but the proportion of low-tech and medium-tech agricultural products exports is

ISSN: 0010-8189

C CONVERTER 2020

Www.converter-magazine.info 
still large, China's agricultural product export technology structure of the market competition pressure is still gradually increased [8]. Wang et al. improved the export technology complexity measurement index by comparing the per capita GDP with the world's per capita GDP. They believed that the export share of China's high-tech complexity agricultural products was about $12.73 \%$, lower than the world average of $20 \%$, and the export technology complexity of China's agricultural products was mainly medium to low [9]. There are few research literatures about the complexity of grain technology. Huang et al. predicted that the total self-sufficiency rate of grain in China will drop from $94.5 \%$ in 2015 to about $91 \%$ in 2025 [10]. Pickson et al. held that there is no causal relationship between grain acreage and grain yield, while energy consumption, average rainfall, labor force and cultivated land area have positive effects on grain crop production, and $\mathrm{CO} 2$ emission, average temperature and temperature change are negatively correlated with grain yield in the short term, while energy consumption, average rainfall, labor force and cultivated land area are significantly positively correlated with grain yield in the short term [11]. ZHOU et al. studied the spatial change of the technical efficiency of grain crops in the field in China, and found that the technical efficiency level of Chinese rice farmers is very high close to 0.9, with little room to improve the efficiency of agricultural input, and the same is true for grain crops such as sorghum and wheat [12]. Natalie et al. studied the dynamic structure of import and export of grain products in Ukraine, and examined the interdependence between the import of agricultural products and the tariffs, consumption tax and value-added tax in the national budget from 2005 to 2019, and concluded that the gradual elimination of agricultural tariffs would lead to the decline of the competitiveness of grain products in Ukraine [13]. Kidane et al. estimated the measurement cost of grain trade volume caused by instrument error in Ethiopia [14]. Since 2000, the average annual grain export of the United States has reached US\$20.575 billion, of which the highest reached US\$ 31.838 billion in 2008. In contrast, China's grain export has reached US\$ 1.697 billion per year, ranking 13th among sample countries. Whether the technical complexity of China's grain export is consistent with the status of export scale remains to be further tested.

\section{Measurement and Analysis of Technical Complexity of Grain Export}

According to the basic measurement thought of previous scholars: the higher the level of agricultural economic development in high-income countries, the higher the technological complexity of agricultural products produced and exported, because they can invest abundant human capital and technological research and development to increase the technological complexity. Therefore, the higher the technological complexity of agricultural products produced and exported, the more advantageous the country is in the export competition. At the same time, in order to eliminate the "large country effect", it is weighted by revealed comparative advantage index, and the calculation formula is as follows:

$$
\operatorname{PRODY}_{i}=\frac{X_{i j} / X_{j}}{W_{i} / W} \times Y_{\mathrm{j}}
$$

$X_{i j}=$ the share of class $\mathrm{i}$ exports from country j; $X_{j}=$ the total export of products from country $\mathrm{j}$; $W_{i=\text { the total }}$ export volume of class i products worldwide; $W$ =the total export worldwide; $Y_{j}=$ the per capita GDP.

The complexity of export technology based on GDP per capita (index) at the national level is based on the assumption that "all export industries have completely homogeneous productivity". In real life, the productivity growth in the agricultural production sector is often lower than that in the manufacturing production sector in the long run, and the complexity of export technology varies from industry to industry. The simple use of national GDP per capita (index) to measure the technical complexity of export of industries does not meet the original theoretical assumption of Hausman's technical complexity measurement model. In order to make the measurement result of the technical complexity index of agricultural products export more scientific, the average GDP of the agricultural labor force in each country is adopted as an alternative index of income, which is more in line with the requirements of the heterogeneity theory, and is expressed by $\mathrm{Y}^{*}$ :

$$
\operatorname{PRODY} Y_{i}=\frac{X_{i j} / X_{j}}{W_{i} / W} \times \mathrm{Y}^{*}
$$

A total of 35 countries (China +OECD member countries in 2010) are included in the sample. The relevant data of ISSN: 0010-8189 
grain exports are derived from the UN COMTRADE, and the per capita GDP of agriculture (constant USD in 2010) is derived from the World Development Indicators Database. The sample time is from 2000 to 2019.

\subsection{Analysis on countries with high technical complexity of grain export}

During the sample period, if the technical complexity of a country's grain export is higher than the average value in more than 15 years, it will be classified as a higher level of export technical complexity, and the country belongs to countries with a high technical complexity of grain export. According to the statistics, Belgium, Canada, Italy, Sweden, the United Kingdom, the United States, Finland, Australia, France and Germany were 10 countries with high export technology complexity. The top three countries for the technical complexity of grain export were the United States, Canada and Australia, with the highest amounts reaching US\$ 146,550, US\$ 181,340 and US\$ 157,480 respectively during the sample period. Among them, in 2019, the technical complexity of grain export in the United States dropped from the first place to the third place, from US\$ 93,050 to US\$ 85,580, a decrease of $8 \%$; Canada rose from US\$ 87,510 to US\$213,370, an increase of $144 \%$, rising from the third place at the beginning of the sample to the first place. The United States, Canada and Australia were the three countries with the highest technical complexity and the largest fluctuation in grain export: Canada had a maximum of US\$ 233,370 in 2019 and a minimum of US\$ 80,470. The technical complexity of grain export in Britain and Sweden showed a downward trend, which dropped by $6.95 \%$ and $16.57 \%$ respectively. Canada and France had obvious rising trends, with Canada increasing by 2.44 times and France increasing by 1.6 times.

Among the countries with high technical complexity of grain export, there were four countries with positive overall growth rate, among which Canada had the highest growth rate of $144 \%$ and Sweden had the lowest growth rate of $-17 \%$. In terms of growth rate, China had an average growth rate of $28 \%$, showing a positive growth. Compared with the ten countries with high technical complexity in grain export, China ranked fifth in the growth rate in technical complexity in grain export.

\subsection{Analysis on countries with medium technical complexity of grain export}

Based on the means comparison rule, the average technical complexity of grain export of the remaining 25 countries was classified. The countries with higher technical complexity of export were Austria, Netherlands, Spain, Japan, Czech Republic, Hungary, Slovakia, Israel and Denmark, a total of 9 countries. On the whole, countries with high technical complexity of grain export were on the rise, with Slovakia, Czech Republic and Hungary showing the most obvious growth trend. Specifically, Slovakia rose to US\$ 65,620 from US\$ 8,310 at the beginning of the sample, with an increase rate of $690 \%$, and its ranking rose from the second lowest in the sequence of countries with higher technical complexity of grain export to the first place. Czech had a greatly fluctuated grain export technology, with a decline rate of $41.7 \%$ in 2001, an increase rate of $62 \%$ in 2011, and a steady upward trend after 2011, with an average annual growth rate of 5.1\%. The average annual growth value of technical complexity of grain export in Hungary was US\$1,040, which showed a trend of rising at first and then falling. The peak value of the sample in the early stage quickly climbed to US\$ 48,010 in 2007, and then dropped sharply to US\$ 32,180 in 2009, showing a relatively stable development trend at the end. Spain's grain exports grew at the slowest rate of technical complexity, with an average annual growth rate of only $2.6 \%$.

\subsection{Analysis on countries with low technical complexity of grain export}

The remaining 16 countries were classified as countries with low technical complexity of grain export: Switzerland, Turkey, Estonia, South Korea and Greece, China, Ireland, Luxembourg, Norway, New Zealand, Mexico, Poland, Chile, Iceland, Portugal and Slovenia. Among them, the technical complexity of grain export in Estonia increased the most, from US\$ 1,840 in 2000 to US\$ 53,720 in 2019, an increase of 29 times, almost catching up with countries with high technical complexity of grain export. Switzerland and Greece showed a

ISSN: 0010-8189

(C) CONVERTER 2020

Www.converter-magazine.info 
downward trend, from the initial US\$ 18,430 to the final US\$ 9,100 respectively, with an overall decline of more than $50 \%$. The technical complexity of grain export in South Korea and Turkey showed a steady and slow upward trend, while that in Ireland showed a V-shaped broken line trend, with the lowest of only US\$ 2,030 in 2009 and the highest of US\$ 8,530 in 2019. China had a grain export volume ranking 13th, which was only US\$ 890 in the year with the highest technical complexity of grain export, ranking second to last, only slightly higher than that of Iceland.

\section{An Empirical Analysis of Multi-factors Affecting the Technical Complexity of Grain Export}

\subsection{Research hypotheses and data source}

Among the top 10 countries in the technical complexity of grain export, Belgium, Sweden, Finland and other small sample countries were excluded, and China is additionally selected as a sample country. Assuming that the technical complexity of grain export is positively correlated with these four major influencing factors, the technical complexity of grain export, grain harvest area, GDP per capita, total grain output and grain output per hectare data of eight sample countries are used. Per capita GDP can objectively measure the true level of a country's economic development, that is, the higher the per capita GDP of a country, the higher the production modernization level and the higher the technical level of grain production in the country, which is more conducive to promoting the technical complexity of grain products export. Grain production scale depends on the land factor input of grain production that the more land factor input into grain production in China, the larger the production scale is, the better it is to form economies of scale and promote the technical complexity of grain export. In this paper, the land factor input is measured by grain harvest area. The total grain output is positively correlated with the level of industrialization, i.e. the greater the total grain output, the more favorable it will be to the improvement of the level of grain industrialization in the country. The total grain output is selected to reflect the level of grain industrialization in a country. The grain yield per hectare is a comprehensive index to measure the scientific and technical talents of a country's grain industry, because excellent breeding before grain production, scientific management in the production process, and storage and storage in the post-production stage are all inseparable from professional and technical talents. The grain stock per hectare is used to define the index of professional and technical talents. Using the total grain output to define the index level of grain industrialization means that the country has a high level of grain industrialization and can complete high-intensity grain production work. The higher the technical level of the professionals in the grain industry, the more advanced breeding and improvement technologies can be provided, and the higher the production technology content of grain products, thus improving the grain yield per unit area in the country. Therefore, the higher the yield per hectare of grain production, the more professionals who master advanced agricultural science and technology in the country.

\subsection{Modeling and empirical results}

Based on the above hypotheses, with the technical complexity of grain export in various countries as the dependent variable, and the level of agricultural modernization, grain production scale, industrialization level and professional talents as the independent variables, an empirical analysis was conducted on the factors affecting the technical complexity of grain export. The samples were selected from the relevant data of China and seven OECD member countries with high level of technical complexity, and the panel data regression model was constructed with the sample period of 2000-2014:

$$
Y_{i t}=\beta_{0}+\beta_{1} X_{1 i t}+\beta_{2} X_{2 i t}+\beta_{3} X_{3 i t}+\beta_{4} X_{4 i t}+\mu_{i t}
$$

$Y_{i t}=$ the technical complexity of grain export, which is an explanatory variable; $i=$ the different countries; $\mathrm{t}=$ the different years; $\mu_{i t}=$ the random disturbance term. Modernization level index $X_{1 t i}$, land factor input $X_{2 \mathrm{it}}$, industrialization level index $X_{3 i t}$ and professional technical index $X_{4 \text { it }}$ are independent variables. Based on the panel data, the F-test was first performed on the specific set form of the model, and the results showed that the

ISSN: 0010-8189 
variable intercept model should be adopted. The regression results were as follows:

$$
\begin{gathered}
Y_{i t}=-36.5104+0.0033 \mathrm{X}_{1 \mathrm{it}}+0.0046 \mathrm{X}_{2 \mathrm{it}}+0.0005 \mathrm{X}_{3 \mathrm{it}}-0.0073 \mathrm{X}_{4 \mathrm{it}} \\
(-2.9648) \quad(17.9208) \quad(2.4077) \quad(2.0859) \quad(-6.6279) \\
R^{2}=0.8409, \quad \overline{R^{2}}=0.8353, \quad \mathrm{~F}=151.2582
\end{gathered}
$$

From the overall fitting degree of the model, the goodness of fit is 0.8409 , and the adjusted goodness of fit is 0.8353 , indicating that the overall interpretation effect of the model is better. The value of $\mathrm{P}$ is 0.0000 , which indicates that the model is significant overall and has good explanatory ability, but the value of D.W statistic of the model is 0.7362 , which indicates that there is obvious positive autocorrelation in the model, so the model is not desirable. Aiming at the autocorrelation problem of the model, the iterative method was used to correct the autocorrelation of the model, and the regression results are as follows:

$$
\begin{gathered}
Y_{i t}=-48.0258+0.0033 \mathrm{X}_{1 \mathrm{it}}+0.0038 \mathrm{X}_{2 \mathrm{it}}+0.0006 \mathrm{X}_{3 \mathrm{it}}-0.0053 \mathrm{X}_{4 \mathrm{it}} \\
(-0.5339)(1.9503)(0.5654)(0.4946)(1.0058) \\
R^{2}=0.9154, \overline{R^{2}}=0.9121, \mathrm{~F}=281.15
\end{gathered}
$$

The goodness of fit of the revised regression model after adjustment is 0.9018 , which shows that the overall interpretation effect is good. The $\mathrm{P}$ value is 0.0000 , which shows that the model is significant overall and has good explanatory ability. The statistical value of D.W is 2.3543 , and the autocorrelation problem in the model is solved at this time, so the model is desirable. Parameter estimation shows that the technical complexity of grain export will increase by US\$ 3.3 for every unit increase in modernization level, that is, per capita GDP; with the expansion of grain production scale, the technical complexity of grain export will increase by US\$ 3.8 for every 10,000 hectares of land input; the technical complexity of grain export will increase by US $\$ 0.6$ for every unit increase of industrialization level; the technical complexity of grain export will be reduced by US\$ 5.3 for every unit increase in professional technology level. In the past 20 years since China's entry into WTO, the accumulation of technology spillovers brought about by opening to the outside world has reached a certain stage. At this time, the improvement of the technical complexity of agricultural products export at a deeper level depends on the improvement of the modernization and industrialization level of agriculture itself. In order to continuously increase the technical complexity level of China's export of agricultural products and form a new value-added production, the accumulation of advanced agricultural production technologies, the invention and popularization of advanced agricultural production machinery and the improvement of advanced agricultural processing technologies should be adopted. It is an important way to improve the technical complexity of grain products export to actively adopt advanced industrial organization forms for production, overcome the drawbacks of small-scale production under household contract for combined production, cultivate modern production organization forms in the form of company-peasant household-cooperative, and further expand the scale of grain production.

\section{Conclusion}

Previous studies on the technical complexity of agricultural exports may have the deficiencies that export technical complexity based on per capita GDP (index) at the national level is based on the assumption that all export industries have homogeneous productivity, that the productivity of agricultural production department is often lower than that of manufacturing production department, and the complexity of export technology varies from industry to industry, and that the simple use of national GDP per capita (index) to measure the export technology complexity of the sub-sectors does not conform to the original theoretical assumptions of houseman's technology complexity measurement model, and also faces challenges from heterogeneity theory. The revised measurement results show that there are 10 countries with high export technical complexity, among which the United States, Canada and Australia are the top three countries, 9 countries with medium and 16 countries with low export technical complexity. In 2019, the technical complexity of China's grain export was US\$ 890, ranking 34th among the sample countries, with an average increase of $28 \%$ during the sample period. Based on the panel data model, the regression results show that the technical complexity of grain export will increase by US\$ 3.3 for every unit of

ISSN: 0010-8189

C CONVERTER 2020

Www.converter-magazine.info 
modernization; with the expansion of grain production scale, the technical complexity of grain export will increase by US $\$ 3.8$ for every 10,000 hectares of land input; the technical complexity of grain export will increase by US\$ 0.6 for every unit of agricultural industrialization. The choice of ways to improve the technical complexity of grain export should focus more on the modernization and industrial development of grain production while actively promoting the technological spillover of the secondary and tertiary industries. Through the accumulation and improvement of grain production and processing technology, as well as the invention and promotion of advanced agricultural production machinery, the technical level of China's grain export will be continuously improved within the industry. It is necessary to further promote the cultivation of grain export brands, further form international high-quality brands with high reputation and good credibility, improve the supervision, management and control system of grain product quality, and complete related supporting warehousing, logistics and other infrastructure, so as to form a new competitive advantage of China's grain export technology.

\section{Acknowledgements}

This research was supported by Applied Economics of Double first-class discipline of Hunan Province, the National Natural Science Foundation of China (Grant No.71573082), the Humanities and Social Sciences Planning Project of the Ministry of Education (Grant No. 14YJA790056).

\section{References}

[1] R. Hausmann, J. Hwang, D. Rodrik., "What you export matters," Journal of Economic Growth, vol.12, no. 1, pp.1-25, 2007.

[2] X.L. Du, W.G. Wang, "Technology Structures of China's Exports and Their Changes: 1980-2003," Economic Research Journal, vol.7, pp.137-151, 2007.

[3] G. Fan, Z.X. Guan, Z.Z. Yao, "Analysis of international trade structure: technical distribution of trade goods," Economic Research Journal, vol.8, pp.70-80, 2006.

[4] M. He, W.M. Tian, C. Andrew, "Technical structure and evolution of agricultural products export trade between China, Japan and Korea--empirical study based on export complexity," Journal of Agrotechnical Economics, vol.5, pp.104-113,2012 .

[5] Z.C. Yin, T. Tian, "Changes of export competitiveness of Chinese agricultural products and international comparison based on analysis of export technology complexity," Journal of Agrotechnical Economics, vol. 1, pp. 77-85, 2013.

[6] Z.Z. Geng, H.F. Xiao, "Technical level and structure of agricultural products export in BRICS countries --- Research based on technical complexity,” Jianghan Academic, vol.37, no. 4, pp.33-39, 2018.

[7] Z.Z. Geng, H.F. Xiao, "Technical level and structure of agricultural product export of RCEP negotiator,” International Business Research, vol.40, no. 4, pp.5-13, 2019.

[8] Z.L. Sun, X.D. Li, “Convergence or Divergence of Technological Structure of World's Agricultural Products Export: A Test Based on Data of Major Agricultural Exporting Countries During 1995-2012," Journal of International Trade, vol. 5, pp. 41-52, 2015.

[9] T.K. Wang, H. Lin, J. Li, “Analysis on export characteristics of agricultural products with different technological complexities in China," World Agriculture, vol.10, pp. 151-157+267, 2018.

[10] J.K. HUANG, W. WEI, CUI Qi, et al., "The prospects for China's food security and imports: Will China starve the world via imports," Journal of Integrative Agriculture. vol.16, no.12.pp.2933-2944, 2017.

[11] R.B. Pickson, G. He, E.B. Ntiamoah, et al., "Cereal production in the presence of climate change in China," Environmental science and pollution research, vol.27, pp. 45802-45813, 2020.

[12] W.B.ZHOU, H.Y.WANG, X.HU, et al., "Spatial variation of technical efficiency of cereal production in China at the farm level," Journal of Integrative Agriculture, vol.20 no.2, pp.470-481, 2021.

[13] Y. S. Natalie, "Analysis of Trends in Taxation and Foreign Economic Operations with Cereal Products in Ukraine," International Journal of Economics Finance and Management Sciences, vol.8 no.5, pp.188, ISSN: 0010-8189 
CONVERTER MAGAZINE

Volume 2021, No. 3

2020.

[14] A.A. Kidane, Z. Deyi, G. E. Bekele, et al., "Quantity Measurement Cost and Reliability of Cereal Commodity Trade: Evidence from Ethiopia," Sustainability, vol.11, no.6, pp.1521, 2019. 